\title{
Impact of merger and acquisition on Indian steel companies- A case study approach
}

\author{
Shrabanti Pal \\ Assistant Professor, Dept. of Commerce, Fakir Chand College, Diamond Harbour, West Bengal, India \\ *Corresponding Author: Shrabanti Pal \\ Email: palsrabanti@gmail.com
}

\begin{abstract}
The present paper is an endeavor to critically analyze the financial health of Indian steel companies during pre and post acquisition period. The study is also an endeavor to analysis the impact of acquisition on the acquirer company after such acquisition. Data are collected from audited balance sheet, profit and loss account of the concerned companies, CMIE data base, BSE and NSE and money control.com. To facilitate the study different types of ratios are selected and paired t-test is applied. The result showed that post acquisition liquidity, profitability, efficiency and cash flows of the selected companies' decline in a significant way. Paired t-test is applied in the study at 0.05 significant levels to compare overall financial position of the selected companies during before and after acquisition. Financial ratios of whole sample show there is a significant deterioration in the mean of all selected ratios of acquirer companies. With a series of merger and acquisition taking place in Indian steel industry so far more than a half of the bidder firms demonstrated depressed financial performance in the post acquisition time as compared to pre acquisition period.
\end{abstract}

Keywords: Corporate reconstruction, Merger and acquisition, Paired t-test, Financial performance of Indian steel companies.

\section{Introduction}

Growth of any industry largely depends on its financial performance. In the present era of globalization corporate sectors are adopting different consolidation strategies to ensure their existence and to achieve greater market share. Merger and acquisition (M\&A) is gaining the pace gradually and becoming one of the most accepted reconstruction strategies among the corporate entities to sustain in the cut throat competitive business environment. A corporate restructuring lead to improve the performance of corporate entities is a debatable issue. Presently corporate sectors are adopting different consolidation strategies like merger and acquisition to expand its growth, improve competitiveness, achieve greater market share and minimize business risk. The Indian steel industry is currently one of the fastest growing industries among the world. It is not only caters to the domestic market in satisfying the domestic demand but also export high quality and low cost steel to the aboard including USA, Russia, South Korea, China etc. It is ranked fourth in crude steel production. Indian steel industry is highly fragmented in nature. Currently it is going through a rough phase. The present paper is an endeavor to critically analyze the financial performance of the acquiring companies during pre and post merger period along with the impact of acquisition on the acquiring companies.

\section{Review of Literature}

Many of the corporate entities are adopting M\&A as survival strategy and to improve competitiveness and synergy over other corporate. Corporate M\&A becomes popular due to liberalization, globalization and technological advancement in the intensely competitive market. M\&A is not a limited phenomenon and it extends worldwide. To compete in a competitive business environment M\&A plays a vital role and it has been found that countries like India, China, Brazil etc, engaged in this consolidation to achieve greater market share and enhance its complete operating synergy during post M\&A era (Zahid and Shah, 2011). But a study showed that no any significant improvement has been found during post merger period of the Australian bidder firms. In this particular study a total sample of 72 companies, 36 acquisitions and their match consisting of control firms are considered (Sharma and $\mathbf{J}$ Ho, 2002). The impact of merger and acquisition is on the liquidity, efficiency and profitability of the firms that participated in the restructuring mechanism in India. For this purpose 13 companies are selected that were engaged in merger during the period $2002-2005$. The result of this study showed an improvement in the liquidity position during post merger (Selvan, et al, 2009). Acquisition of large scale firm tends to experience negative post merger performance in all aspect (Ramaswamy and Waegelein, 2003). Another study by Beena P.L (2004) conducted on Indian manufacturing firms to measure the significant positive changes over the post merger period in terms of profitability, liquidity, and efficiency and capital ratios. But the result showed no significant improvement in the financial performance of the acquiring firms. Ravenceraft and Scherer (1989) examined financial performance of target firms during 1957-77 in USA. Their investigation was included 2732 lines of US manufacturing companies. The study is showing a significant negative impact of $13.34 \%$ on post merger profitability and concludes that merger is not effective in improvement of the profitability during post merger period. Henry, et.al. (1992) investigated the 50 largest U.S acquisitions during the period of Jan 1979 to June 1984. They analyzed the post merger operating performance of the combined firms using industry median as bench mark. They observed that operating performance improves significantly after merger; however the study has been criticized for using industry median firms as a benchmark. Cornett \& Tehranian (1992); Switzer (1996), Ghosh (2001) found M\&A firms shows significantly increase in operating performance. Pawaskar (2001) found 
that liquidity and shareholders' fund significantly increased after M\&A. Rau and Vermalon (1997) has investigated that the determinants of poor performance of the bidding firms having low book to market value ratio in general make poor decisions regarding M\&A. Empirical testing of post merger performance of Indian companies has so far been proved uncertain in order to derive any meaningful inference. The studies were also highly skewed in favour of a particular sector especially manufacturing ones and have a time period bias as only short time intervals were chosen to measure the performance.

\section{Statement of Problem}

M\&A is the recent trend of corporate entities in all over the world to achieve economies of scale, growth, diversification, operating synergy, market share enhancement, etc. Liberalization and globalization resulted into monopolistic approach of the business houses in terms of M\&A. Consolidation of business houses becomes more popular in the recent times as survival strategies. Steel industry is an integral part of Indian economy and witnessing big acquisition. At present, good quality of product becomes more acceptable than maximum quantity of product. In the era of globalization each company tries to minimize the cost and maximize the profit quotient to achieve greater market share. In this competitive scenario no one company has competitive advantage in terms of cost minimization and market share maximization. In the present study it is an attempt to examine financial performance of the acquirer companies during pre and post acquisition period and also to measure impact of acquisition on the acquirer companies on financial health.

\section{Objectives}

1. To study and compare the financial health of the sample companies during pre and post acquisition time in terms of liquidity, leverage, efficiency, profitability and cash flows.

2. To study the impact of acquisition on the acquirer company after such acquisition.

\section{Methodology}

Sample: Convenience sampling technique is applied in the present study for selecting the sample companies. As the complete source list of all steel companies of India is not readily available thus convenience sampling method is applied in the present study. The study includes three sample companies like Tata Steel, Hindalco and JSW Steel

Variable Selection: For the purpose of this study total 16 conventional financial ratios were selected from five different categories like liquidity, leverage, efficiency, profitability and cash flows. From liquidity two ratios namely current ratio (CR) and quick ratio (QR) were selected followed by debt equity ratio (DER) and interest coverage ratio (ICR) from leverage, inventory turnover ratio (ITR), assets turnover ratio (ATR), sales to fixed assets ratio (STFA), working capital turnover ratio (WCTR) from efficiency and profit before interest and tax margin (PBITM), net profit margin (NPM), return on assets (ROA), return on net worth (RONW), return on capital employed (ROCE), earning per share (EPS), from profitability and cash flow margin ratio (CFMR) and operating cash flow ratio (OCFR) from cash flow.

Data and Source of Data: The present study is basically analytical in nature and based on secondary data. Data are collected form CMIE database and also from audited Profit \&Loss Account, Balance Sheet, reported financial ratios of the concerned company's websites, and financial sites like BSE, NSE and moneycontrol.com.

Study Period: The present study is an endeavor to analyze the financial health of the sample companies prior and after the acquisition. Ten years prior and ten years after the acquisition have been considered for Tata Steel and Hindalco and five years each prior and after acquisition are considered for JSW steel in the present study. The study period is comprised of 20 years since 1999-2000 to 201617.

\section{Research Methodology}

1. Financial ratios from different categories like liquidity, leverage, profitability, efficiency and cash flows are selected to analyze the financial condition of the selected companies during pre and post acquisition period. Data are presented in a tabular form along with charts like column chart to facilitate the study. Column chart is used in the study to show the data changes over a period of time and for illustrating comparison.

2. Paired sample t-test is applied in the present study to evaluate the improvement of financial performance of acquirer during the post acquisition period over pre acquisition period. The test is used to determine the significant difference over pre and post acquisition era. The null hypothesis indicates no significant difference has been found after acquisition compared to prior to acquisition. A positive t-value indicates higher mean value of the variable during post acquisition time. Thus, high positive $t$-value $(|t|>2)$ along with low $p$-value $(\mathrm{p}<0.05)$ implies significant improvement of particular ratio after acquisition and vice versa.

\section{Hypothesis}

$\mathrm{H}_{0}$ : There is no significant improvement of financial health of sample companies after acquisition.

$\mathrm{H}_{1}$ : There is significant improvement of financial health of sample companies after acquisition.

\section{Data Analysis and Interpretation \\ Financial Analysis on Performance of Sample Steel Companies}




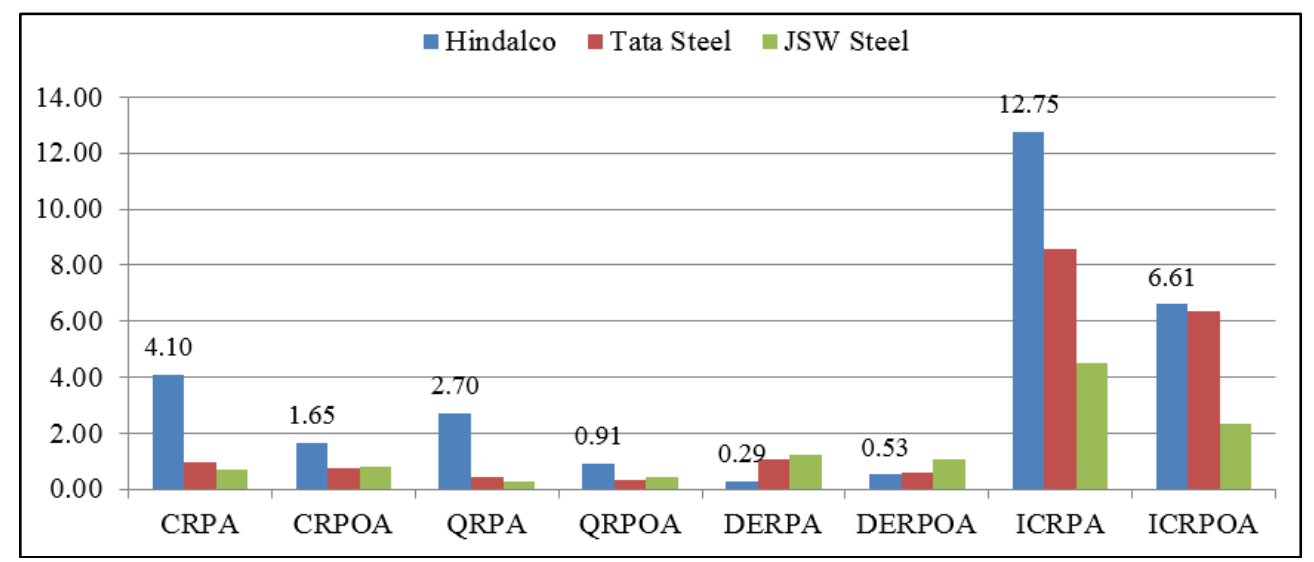

Fig. 1: Liquidity and leverage position of sample companies before and after acquisition

The liquidity ratios CRPA (current ratio pre acquisition), CRPOA (current ratio post acquisition), QRPA (quick ratio pre acquisition), and QRPOA (quick ratio post acquisition) of the sample companies are selected for the present study. On the other hand leverage ratios like DERPA (debt equity ratios pre acquisition), DERPOA (debt equity ratios post acquisition), ICRPA (Interest Coverage Ratio pre acquisition) and ICRPOA (Interest Coverage Ratio post acquisition) are selected during the study period. The mean of liquidity ratios are used to explain the financial health of the companies before and after acquisition. It is clear from the above graph (Fig. 1) those two companies like Hindalco and Tata steel have high liquidity before acquisition compared to after acquisition. But in case of JSW steel both the ratios are showing certain improvement during post acquisition period. In contrast DER of Hindalco is showing a significant increase after acquisition compared to pre acquisition period. But for other two companies namely Tata Steel and JSW Steel the same ratio is declined during post acquisition period. ICR of the sample companies is exhibiting less compared to pre acquisition period indicating the companies are suffering financial crunches after acquisition and unable to cover interest expenses.

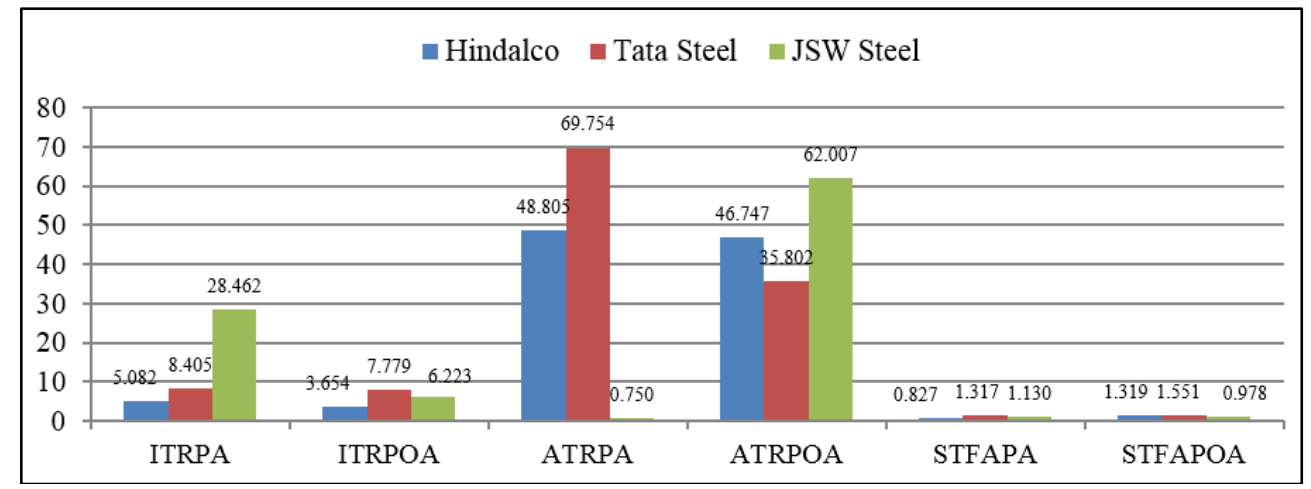

Fig. 2: Efficiency position of sample companies before and after acquisition

The chart (see Fig. 2) is showing different efficiency ratios like inventory turnover ratio, assets turnover ratio, and sales to fixed assets turnover ratio of the sample companies during pre and post acquisition period. The mean of ITRPA (inventory turnover ratio pre acquisition) is showing more for the sample companies compared to ITRPOA (inventory turnover ratio post acquisition). Inventory turnover ratio during pre acquisition period of JSW Steel was quite high in contrast to post acquisition period. It shows a sharp decline for this sample company from 28.462 to 6.223 during the study period. The mean of assets turnover ratio during post acquisition period (ATRPOA) is exhibiting certain downfall in case of Hindalco and Tata steel compared to mean of assets turnover ratio during pre acquisition period (ATRPA). But in case of JSW Steel it shows rising trend after acquisition. Another ratio sales to fixed assets post acquisition (STFAPOA) is high for two sample companies Hindalco and Tata steel in comparison to sales to fixed assets pre acquisition (STFAPA) whereas the same ratio is less during the post acquisition in case of JSW Steel. 


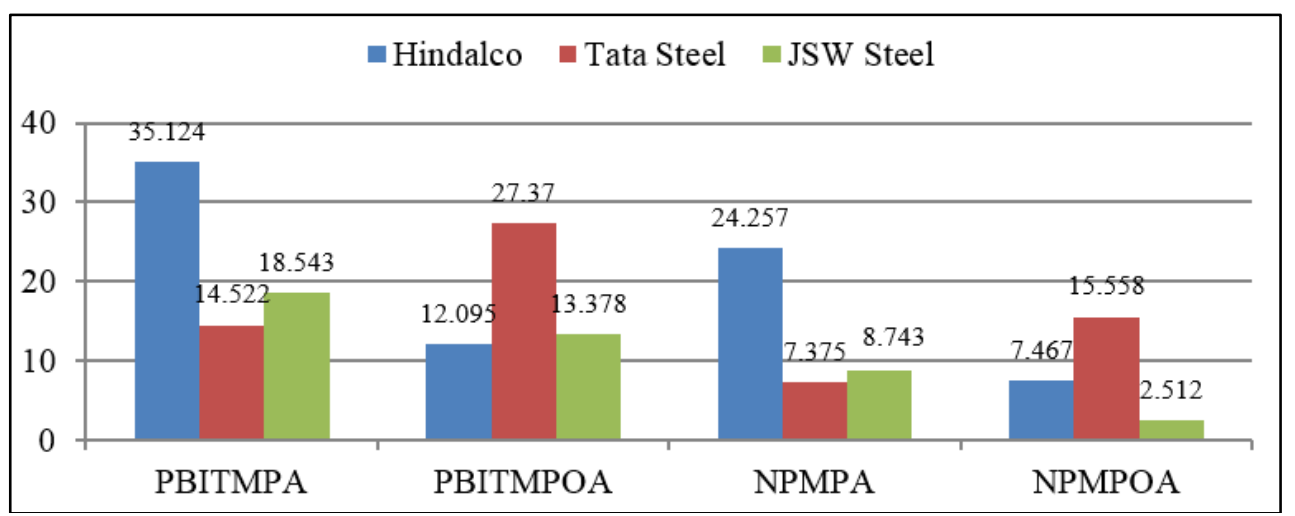

Fig. 3: Profit margin position of sample companies before and after acquisition

The chart (Fig. 3) is showing the mean value of profit margin ratios of the sample companies during pre and post acquisition period. Margin variables are proxy by profit before interest and tax margin pre acquisition (PBITMPA), profit before interest and tax margin post acquisition (PBITMPOA), net profit margin pre acquisition (NPMPA) and net profit margin post acquisition (NPMPOA). PBIT of two sample companies Hindalco and JSW Steel is deteriorated after acquisition but on the other hand the same ratio shows improvement for Tata Steel. NPM of two companies (Hindalco and JSW Steel) declined after acquisition while NPM of Tata Steel reports improvement after acquisition.

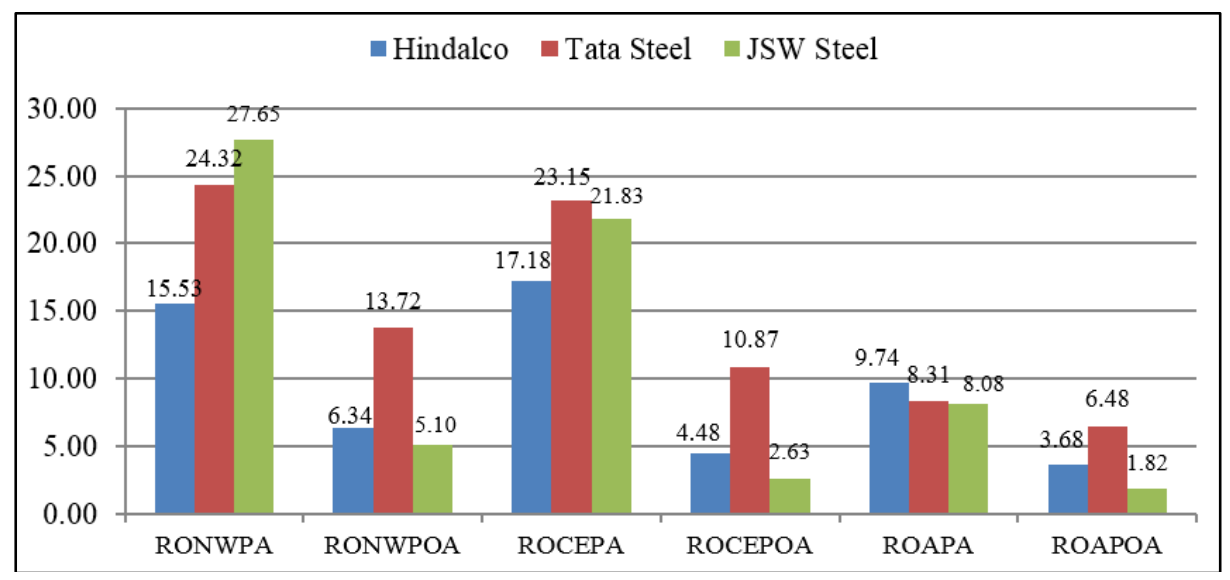

Fig. 4: Return position of sample companies before and after acquisition

The above chart (Fig. 4) is reporting the average value of the profitability performance indicators during pre and post acquisition of the sample companies under study. Profitability variables are proxied by return on net worth pre acquisition (RONWPA), return on net worth post acquisition (RONWPOA), return on capital employed pre acquisition (ROCEPA), return on capital employed post acquisition (ROCEPOA), return on assets pre acquisition (ROAPA) and return on assets post acquisition (ROAPOA). RONW of three sample companies is not at all improved after such acquisition. ROCE and ROA of the companies are also showing deterioration during post acquisition period for all three sample companies.

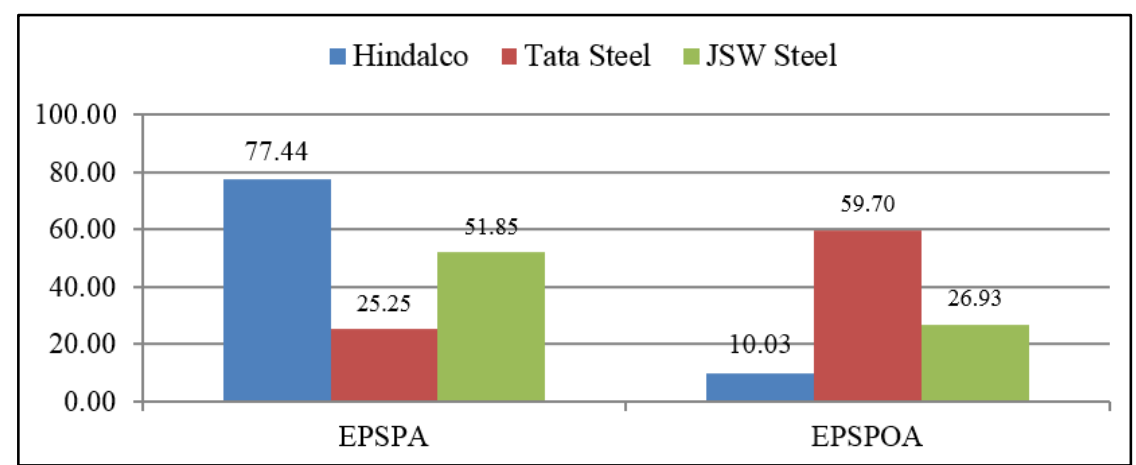

Fig. 5: Earnings per share (EPS) of sample companies before and after acquisition 
The above chart (Fig. 5) is reporting the average value of capital performance indicators of the sample companies before and after acquisition. Capital performance variable is proxied by earnings per share pre acquisition (EPSPA) and earnings per share post acquisition (EPSPOA). Out of three companies EPS of two companies namely Hindalco and JSW Steel deteriorated radically after such reconstruction while EPS of Tata Steel is showing improvement after such acquisition.

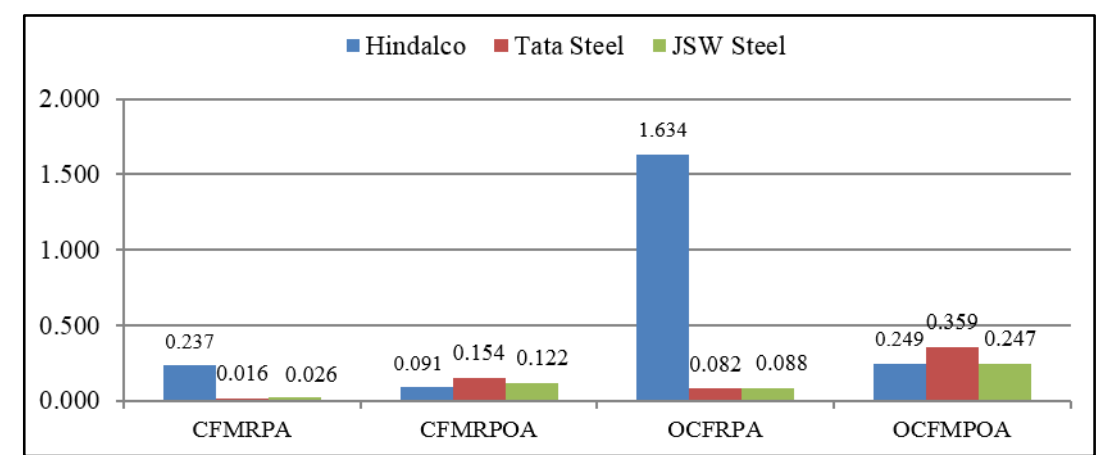

Fig. 6: Cash flow performance indicators of sample companies before and after acquisition

The chart (Fig. 6) is showing cash flow performance of the sample companies during pre and post acquisition period. The cash flow ratios are proxied by cash flow margin ratio pre acquisition (CFMRPA), cash flow margin ratio post acquisition (CFMRPOA), operating cash flow ratio pre acquisition (OCFRPA) and operating cash flow ratio post acquisition (OCFRPOA). CFMR of two companies Tata Steel and JSW Steel is showing improvement after such reconstruction but no improvement has been found in case of Hindalco. The other ratio OCFR is also showing certain deterioration during post acquisition period for Hindalco. But the same ratio is demonstrating increase in case of Tata Steel and JSW Steel after acquisition.

\section{Statistical Analysis of Liquidity Position of Sample Companies}

SPSS 17.0 is used to run paired t-test in the present study

Table 1: Impact of acquisition on liquidity ratios of sample companies

\begin{tabular}{|l|c|c|c|c|c|c|c|c|}
\hline \multirow{2}{*}{$\begin{array}{c}\text { Name of } \\
\text { Companies }\end{array}$} & \multicolumn{9}{|c|}{ CR } & Post & t-test & Sig & Pre & Post & t-test & Sig \\
\cline { 2 - 9 } \\
\hline Hindalco & 4.0950 & 1.6480 & -3.633 & .005 & 2.6980 & .9080 & -3.252 & .010 \\
\hline Tata Steel & .9520 & .7310 & -2.343 & .044 & .4220 & .3100 & -1.095 & .302 \\
\hline JSW Steel & .7033 & .7833 & .967 & .378 & .2800 & .4517 & 3.686 & .014 \\
\hline
\end{tabular}

after acquisition period. Such decrease is significant at 0.05

The above table (Table 1) is showing the liquidity conditions of three acquired sample companies under the study. Liquidity condition of the sample companies is measured through two proxy ratios namely current ratio $(\mathrm{CR})$ and quick ratio $(\mathrm{QR})$. In case of Hindalco and Tata Steel, CR is showing declining trend during the post acquisition period. CR of Hindalco is showing a mean of 4.095 and 1.648 during the pre and post acquisition period respectively. On the other hand CR of Tata Steel is presenting 0.9520 and 0.7310 respectively during before and levels with high t-value. In contrast, mean of CR of JSW Steel is indicating an insignificant increase after the acquisition which evident from low t-value (0.967) and high p-value (0.378). QR of Hindalco and Tata Steel demonstrating decrease after acquisition in a significant $(\mathrm{t}=-$ 3.252, $\mathrm{p}$-value $=0.010)$ and insignificant $(\mathrm{t}=-1.095$, $\mathrm{p}$-value $=$ 0.302 ) manner. In contrast, QR of JSW Steel during pre and post acquisition period is 0.2800 and 0.4517 respectively. Such increase is significant with high $|\mathrm{t}|$-value $=3.686$ and low $\mathrm{p}$-value $=0.014)$.

Table 2: Impact of acquisition on leverage ratios of sample companies

\begin{tabular}{|l|c|c|c|c|c|c|c|c|}
\hline \multirow{2}{*}{$\begin{array}{c}\text { Name of } \\
\text { Companies }\end{array}$} & \multicolumn{4}{|c|}{ DER } & \multicolumn{4}{c|}{ ICR } \\
\cline { 2 - 9 } & Pre & Post & t-test & Sig & Pre & Post & t-test & Sig \\
\hline Hindalco & .2930 & .5280 & 4.289 & .002 & 12.753 & 6.608 & -3.357 & .008 \\
\hline Tata Steel & 1.0510 & .6220 & -.0828 & .021 & 8.6000 & 6.3460 & -.568 & .584 \\
\hline JSW Steel & 1.2317 & 1.0500 & -1.184 & .290 & 4.4883 & 2.3683 & -3.740 & .013 \\
\hline
\end{tabular}

Debt equity ratio indicates how much debt a company is using to finance its assets relative to the value of shareholder's equity. From the above table (Table 2) it reveals that DER of Hindalco has grown up significantly $(|\mathrm{t}|=4.289, \mathrm{p}=0.002)$ during post acquisition period implying major use of debt finance towards its assets over 
shareholders' fund. On the other hand ICR of the concerned company is reporting significant $(|t|=3.357, \quad p=0.008)$ decrease after the acquisition means that the company is not capable enough to generate income to cover its interest expenses. In case of Tata Steel, DER and ICR are showing significant $(|\mathrm{t}|=0.828, \mathrm{p}=0.021)$ and insignificant $((|\mathrm{t}|=0.568$, $\mathrm{p}=0.584)$ minimal decrease after acquisition. It implies that the company is using less debt towards its assets but failed to earn enough income to meet its interest expenditure. DER of JSW Steel reports an insignificant decrease $(|t|=1.184, p=$ 0.290 ) and ICR is demonstrating a significant increase $(|\mathrm{t}|=3.740, \mathrm{p}=0.013)$ during post acquisition indicating the reduction in debt finance and risen up of income relative to interest cover.

Table 3: Impact of acquisition on efficiency ratios of sample companies

\begin{tabular}{|l|c|c|c|c|c|c|c|c|c|c|c|c|}
\hline \multirow{2}{*}{$\begin{array}{c}\text { Name of } \\
\text { Companies }\end{array}$} & \multicolumn{1}{|c|}{ ITR } & \multicolumn{10}{|c|}{ ATR } & \multicolumn{4}{|c|}{ STFA } \\
\hline Hindalco & 5.08 & Post & t-test & Sig & Pre & Post & t-test & Sig & Pre & Post & t-test & Sig \\
\hline Tata Steel & 8.41 & -3.09 & .013 & 48.81 & 46.75 & -.51 & .616 & .83 & 1.32 & 1.56 & .154 \\
\hline JSW Steel & 28.46 & -.529 & .609 & 69.75 & 35.80 & -10.79 & .000 & 1.32 & 1.55 & .625 & .548 \\
\hline
\end{tabular}

Table 3 reports operating efficiency performance indicators preceding and succeeding the acquisition of 3 sample Indian steel companies. Efficiency variables are proxy by inventory turnover ratio (ITR), assets turnover ratio (ATR), working capital turnover ratio (WCTR), and sales to fixed assets (STFA). ITR of all three sample companies is reporting declining trend during the post acquisition period in a both significant and insignificant manner. ITR shows significant decline for Hindalco and JSW Steel but such decrease is not significant for Tata Steel during post acquisition period. Assets turnover ratio (ATR) is showing significant deterioration for two companies namely Tata Steel and JSW Steel but statistically insignificant for Hindalco $(|\mathrm{t}|=0.51, \mathrm{p}=0.616)$. Sales to fixed assets (STFA) of two sample companies HIndalco and Tata Steel is showing insignificant increase during post acquisition period implying that companies are efficiently using their fixed assets to generate sales. On the other hand the mean of STFA demonstrates significant reduction $(|t|=2.528, p=0.05)$ after acquisition indicating less efficient use of fixed assets towards sales creation.

Table 4: Impact of acquisition on profitability ratios of sample companies

\begin{tabular}{|c|c|c|c|c|c|c|c|c|c|c|c|c|}
\hline \multicolumn{13}{|c|}{ Margin Ratios } \\
\hline \multirow{2}{*}{$\begin{array}{c}\text { Name of } \\
\text { Companies }\end{array}$} & \multicolumn{4}{|c|}{ PBITM } & \multicolumn{4}{|c|}{ NPM } & \multicolumn{4}{|c|}{ EPS } \\
\hline & Pre & Post & t-test & Sig & Pre & Post & t-test & Sig & Pre & Post & t-test & Sig \\
\hline Hindalco & 35.12 & 12.09 & -7.058 & .000 & 24.26 & 7.47 & -8.71 & .000 & 77.44 & 10.03 & -6.028 & .000 \\
\hline Tata Steel & 14.52 & 27.37 & 2.772 & .022 & 7.37 & 15.56 & 2.11 & .064 & 25.25 & 59.70 & 3.301 & .009 \\
\hline JSW Steel & 18.54 & 13.37 & -2.060 & .094 & 8.74 & 2.51 & -3.63 & .015 & 51.86 & 26.93 & -.782 & .470 \\
\hline \multicolumn{13}{|c|}{ Return Ratios } \\
\hline & \multicolumn{4}{|c|}{ RONW } & \multicolumn{4}{|l|}{ ROCE } & \multicolumn{4}{|l|}{ ROA } \\
\hline & Pre & Post & $t$-test & Sig & Pre & Post & t-test & Sig & Pre & Post & t-test & Sig \\
\hline Hindalco & 15.53 & 6.34 & -6.958 & .000 & 17.18 & 4.48 & -11.166 & .000 & 9.74 & 3.68 & -15.928 & .000 \\
\hline Tata Steel & 24.32 & 13.72 & -1.365 & .205 & 23.15 & 10.87 & -1.553 & .155 & 8.31 & 6.48 & -.628 & .546 \\
\hline JSW Steel & 27.65 & 5.10 & -4.831 & .005 & 21.83 & 2.63 & -8.740 & .000 & 8.08 & 1.86 & -6.940 & .001 \\
\hline
\end{tabular}

The above table (Table 4) is illustrating the profitability ratios of sample companies. Profit before interest and tax margin (PBITM) of Hindalco and JSW Steel is reporting a significant and insignificant decrease $(|t|=7.058, p=0.000)$ $(|\mathrm{t}|=2.060, \quad \mathrm{p}=0.094)$ respectively after the acquisition indicating less operating efficiency during post acquisition period. In case of Tata Steel a significant improvement $(|t|=2.772, p=0.022)$ has been found after acquisition (27.37) compared to prior to acquisition (14.52). It implies an operating improvement after such acquirement. NPM and EPS of Tata Steel also showing a statistical significant improvement after the acquisition indicating a successful synergic advantage for this concerned companies due to acquisition. In contrast, NPM and EPS of Hindalco and JSW Steel are reporting significant reduction during post acquisition period evidencing failure of such consolidation in terms of cost control, pricing policies and production efficiency. Above all a consistent decrease of EPS is an indication of continuous deterioration of company's earning power. It is also reporting return ratios of 3 sample companies. Three return ratios are considered for the present study namely return on net worth (RONW), return on capital employed (ROCE) and return on assets (ROA). RONW reveals that how well the company utilizing the shareholders' investment to create returns for them. RONW of all sample companies is showing decreasing trend during the post acquisition period. RONW of Hindalco and JSW steel is showing statistically significant decrease with high tvalue $(|t|>2)$ and low $p$-value $(p<0.05)$. However, in case of Tata Steel deterioration of RONW is insignificant because of low $\mathrm{t}$-value $(\mathrm{t}=-1.365)$ and high $\mathrm{p}$-value $(\mathrm{p}=0.205)$. ROCE implies that how efficiently the company can 
generate profits from its capital employed. ROCE of three sample companies is reporting a decline trend after the acquisition and such deterioration is significant for Hindalco and JSW steel but insignificant for Tata Steel. ROA is another profitability ratio that measures the net income produced by total assets during a period by comparing net income to the average total assets. ROA of Hindalco, Tata Steel and JSW Steel is showing 3.68, 6.48 and 1.86 respectively during the post acquisition period compared to 9.74, 8.31 and 8.08 during the pre acquisition period. Such deterioration is significant in case of Hindalco and JSW Steel but highly insignificant for Tata Steel.

Table 5: Impact of acquisition on cash flow ratios of sample companies

\begin{tabular}{|c|c|c|c|c|c|c|c|c|}
\hline \multirow{2}{*}{$\begin{array}{c}\text { Name of } \\
\text { Companies }\end{array}$} & \multicolumn{4}{|c|}{ CEMR } & \multicolumn{4}{|c|}{ OCFR } \\
\hline & Pre & Post & $t$-test & Sig & Pre & Post & $t$-test & Sig \\
\hline Hindalco & .23677 & .0908 & -3.962 & .003 & 1.634 & .249 & -4.569 & .001 \\
\hline Tata Steel & .01649 & .1542 & 3.774 & .004 & .0822 & .3588 & 4.149 & .002 \\
\hline JSW Steel & .02569 & .12173 & 6.937 & .001 & .08757 & .24678 & 4.346 & .007 \\
\hline
\end{tabular}

The above table (Table 5) is showing CFMR and operating cash flow ratio (OCFR) of three sample companies. CFMR measures the ability of company to translate sales into cash. CFMR of Hindalco is showing a significant decrease after the acquisition whereas the same ratio is reporting significant increase for the rest of two companies (Tata Steel and JSW Steel) during the post acquisition period. Another ratio operating cash flow ratio (OCFR) indicates generation of enough cash to pay off the short term debt. OCFR of Hindalco is showing 1.634 and 0.249 during pre and post acquisition period respectively and such decrease is statistically significant at 0.05 levels. But it has been observed that the ratio significantly improved during the post acquisition period of Tata Steel and JSW Steel. OCFR of Tata Steel and JSW Steel significantly increased during the study period indicating that the companies are able to generate cash to pay off its short term debt.

Table 6 Analysis of overall impact of acquisition on financial performance of sample companies

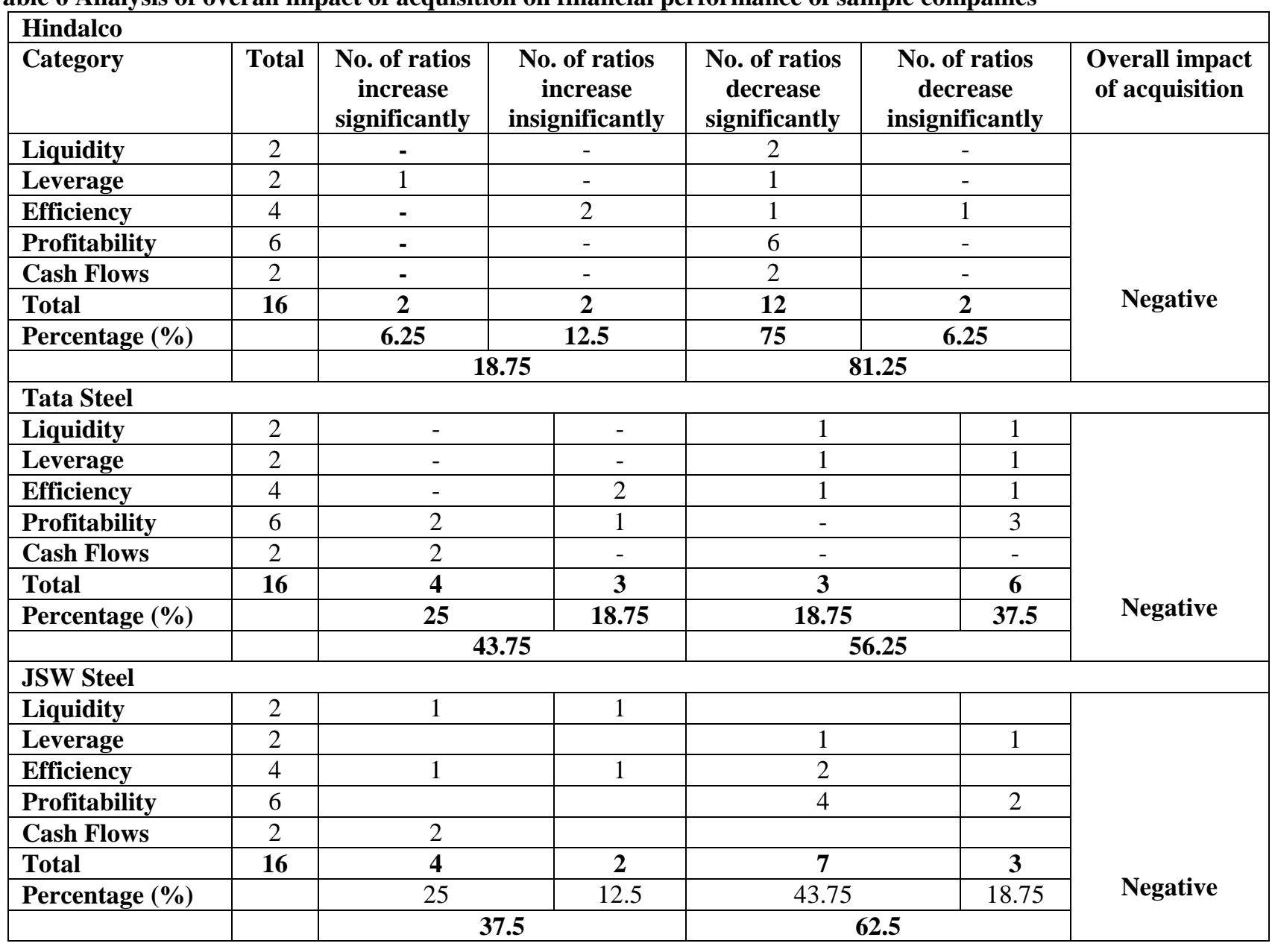


In case of Hindalco, out of 16 ratios 1 ratio of leverage (DER) shows significant increase $(6.25 \%)$ indicating high debt burden of the company after acquisition, whereas 1 ratio shows insignificant increase during post acquisition period. Overall $12.5 \%$ increase has been found after acquisition. In contrast, 12 ratios $(75 \%)$ decrease significantly and 4 ratios $(12.5 \%)$ decrease insignificantly respectively during post acquisition period. It indicates that the company faced $87.5 \%$ decrease during post acquisition time. Hence, the overall impact of acquisition on the financial health of the concerned company is negative.

Likewise, 4 ratios out of $16(25 \%)$ show significant increase and 3 ratios $(18.75 \%)$ insignificant increase respectively after acquisition in case of Tata Steel. On the other hand 3 ratios out of 16 ratios (18.7\%) and 6 ratios (37.5\%) shows significant and insignificant decline after acquisition. Thus, the financial health of the concerned company demonstrates total $56.25 \%$ downturn compared to $43.75 \%$ improvement after the reconstruction. Thus it can be concluded that the company's financial health is not at all improving during the post acquisition.

In case of JSW Steel, 4 ratios (25\%) exhibit significant increase and 2 ratios (12.5\%) insignificant increase respectively in post acquisition period. Hence, the company witnessed $37.5 \%$ increase due to this acquisition. But 7 ratios $(43.75 \%)$ and 3 Ratios $(18.75 \%)$ shows significant and insignificant downturn during post acquisition implying total of $62.5 \%$ decline in the financial performance. Thus it can be said that impact of acquisition is negative.

\section{Conclusion}

While no means conclusive, the present paper has gone some way to contribute to the investigation of improvement of the firms during post acquisition period. In the context of economic reforms in general and subsequent wave of merger and acquisition in particular, the present paper is an endeavor to scrutinize the impact of acquisition on financial performance of the sample companies. With a series of merger and acquisition taking place in Indian steel industry so far more than a half of the bidder firms demonstrated depressed financial performance in the post acquisition time as compared to pre acquisition period. The findings of the paper showed post acquisition liquidity, profitability, efficiency and cash flows of the selected companies' declines and deteriorated in a significant way. Paired t-test is applied in the study at 0.05 significant levels. The comparison of before and after acquisition financial ratios of whole sample shows there is a significant deterioration in the mean of all selected ratios of acquirer. Overall financial position of the selected companies is significantly deteriorated during the post acquisition time. Hence, it can be said that corporate restructuring failed to achieve desired goal in respect of improvement of financial condition for the selected companies during post acquisition time.

\section{References}

1. Beena, P.L., 2004. Towards Understanding Waves in Indian Corporate Sector- A Comparative Perspective. Centre for Development Studies (CDS), 1-44.

2. Comett, Marcia M., and Hassan Tehranian. Changes in Corporate Performance Associated with Bank Acquisitions. Journal of Financial Economics. 1992;31:211-234.

3. Sharma, D.S. and J. Ho, 2002. The Impact of Acquisitions on Operating Performance: Some Australian Evidence. Journal of Business Finance \& Accounting. 29(1\&2).

4. Ghosh, A. 2001. Does Operating Performance Really Improve Following Acquisition? Journal of Corporate Finance. 2001;7(2):151-178.

5. Pawaskar. V, 2001, Effect of merger on corporate performance in India, Vikalpa,26(1)

6. Ravenscraft, D.J. and Scherer, F.M. The Profitability of Mergers. International Journal of Industrial Organization. 1989;7:101-116. http://dx.doi.org/10.1016/01677187(89)90048-9

7. Ramaswamy KP, James Waegelein F. Firm financial performance following Mergers Reviews of Quantative finance and Accounting. 2003;20:115-126.

8. Rau and Vermaelen. Glamour, Value and the Post Acquisition Performance of Acquiring Firms. Journal of Financial Economics, 1997;49:222-253.

9. Selvam, M, M. Babu, G. Indhumathi and B. Ebenezer. Impact of mergers on the corporate performance of acquirer and target companies in India. Journal of Modern Accounting and Auditing. 2009;5(11):55.

10. Switzer, J.A. Evidence on Real Gains in Corporate Acquisitions. Journal of Economics and Business. 1996;48(5):443-460.

11. Vardhana, P. Effect of Mergers on Corporate Performance in India, Vikalpa. 2001;26(1):19-32

12. Zahid, N. \& Shah, A.M. 2011. Merger and Acquisitions in International Business, European Scientific Journal. pp-43-56.

How to cite this article: Pal S. Impact of merger and acquisition on Indian steel companies- A case study approach. J Manag Res Anal. 2018;5(4):455-462. 